\title{
Body mass index is not associated with early onset cataract in the 45 and Up cohort study
}

\author{
Jiaqing Zhang ${ }^{1 \#}$, Wei Wang ${ }^{1 \#}$, Guangyao Yang ${ }^{2 \#}$, Jason $\mathrm{Ha}^{3}$, Xuhua Tan ${ }^{1}$, Xianwen Shang ${ }^{3}$, Zhuoting Zhu ${ }^{4}$, \\ Xiaotong Han ${ }^{1}$, Zhenzhen Liu ${ }^{1}$, Lei Zhang ${ }^{3,5,6,7}$, Mingguang $\mathrm{He}^{1,3,8}$, Lixia Luo ${ }^{1}$
}

${ }^{1}$ State Key Laboratory of Ophthalmology, National Clinical Research Center, Zhongshan Ophthalmic Center, Sun Yat-sen University, Guangzhou, China; ${ }^{2}$ Department of Ophthalmology, Municipal Hospital of Chifeng, Inner Mongolia Autonomous Region, Chifeng, China; ${ }^{3}$ Centre for Eye Research Australia, Royal Victorian Eye and Ear Hospital, Melbourne, Australia; ${ }^{4}$ Department of Ophthalmology, Guangdong Academy of Medical Sciences, Guangdong Provincial People's Hospital, Guangzhou, China; ${ }^{5}$ Artificial Intelligence and Modelling in Epidemiology Program, Melbourne Sexual Health Centre, Alfred Health, Melbourne, Australia; ${ }^{6}$ Central Clinical School, Faculty of Medicine, Monash University, Melbourne, Australia; ${ }^{7}$ Department of Epidemiology and Biostatistics, College of Public Health, Zhengzhou University, Zhengzhou, China; ${ }^{8}$ Ophthalmology, Department of Surgery, University of Melbourne, Melbourne, Australia

Contributions: (I) Conception and design: L Luo; (II) Administrative support: M He, L Zhang; (III) Provision of study materials or patients: L Luo; (IV) Collection and assembly of data: J Ha, X Tan, Z Zhu, X Shang, X Han, Z Liu; (V) Data analysis and interpretation: J Zhang, W Wang, G Yang; (VI) Manuscript writing: All authors; (VII) Final approval of manuscript: All authors.

"These authors contributed equally to this work.

Correspondence to: Prof. Lixia Luo. State Key Laboratory of Ophthalmology, Zhongshan Ophthalmic Center, Sun Yat-sen University, Guangzhou 510623, China. Email: luolixia@mail.sysu.edu.cn.

Background: Body mass index (BMI) has been reported to be associated with age-related cataract, whereas its impact on early onset cataract (EOC) remains unknown.

Methods: A total of 73,007 individuals aged 45-55 years who had no previous cataract surgeries at baseline were enrolled from the population-based 45 and Up Study. BMI was calculated based on self-reported height and weight from the baseline questionnaire. Data on cataract surgeries were obtained from the Medicare Benefits Schedule database. EOC was defined as cataract surgically treated prior to 65 years of age. A Cox proportional hazards regression was used to assess the association between BMI and the incidence of EOC during the follow-up.

Results: A total of 1,764 participants underwent cataract surgery over 643,717 person-years of followup. No significant association was observed between BMI and EOC (P for trend 0.35). Among participants who drank 5 to 7 alcoholic drinks per week, a $73 \%$ and $27 \%$ reduction in the risk of EOC was observed in participants with a BMI of $18.5-19.99$ and $25.0-27.49 \mathrm{~kg} / \mathrm{m}^{2}$, respectively, compared to those with a BMI of $20.0-22.49 \mathrm{~kg} / \mathrm{m}^{2}$.

Conclusions: No association was identified between BMI and the incidence of EOC. Moderate alcohol intake may be protective against EOC.

Keywords: Early-onset cataract; risk factor; Australian; 45 and Up Study; cohort

Submitted May 28, 2021. Accepted for publication Oct 12, 2021.

doi: 10.21037/atm-21-2775

View this article at: https://dx.doi.org/10.21037/atm-21-2775

\section{Introduction}

Cataract is the leading cause of visual impairment and blindness worldwide (1). While its prevalence is increasing in patients over 65 years old (2) related to the predominant form of age-related cataract, there is a smaller but significant subtype of cataract that can develop before the age of 65 with considerable impact on a patient's quality of life, commonly defined as early onset cataract (EOC). In 
addition to visual impairment, patients with EOC also have a higher risk of cancer (3) and cardiovascular disease (4) due to insufficient anti-oxidative activity.

Earlier studies have suggested that EOC may be associated with diabetes, sedentary lifestyle, atopy, high myopia, long-term corticosteroid therapy, and smoking (5). However, these data are inconsistent between studies, and there is a relative paucity of literature exploring the etiology and related risk factors of EOC in a population-wide cohort. Given that the cataractogenesis in these patients may be secondary to potentially modifiable risk factors, further investigations are warranted to clarify these associations.

Elevated body mass index (BMI) is a significant risk factor for a multitude of diseases, but predominantly metabolic disorders including cardiovascular disease and diabetes. However, a clear association between BMI and age-related cataract (ARC) has not been fully established, with findings across observational and prospective studies ranging from a positive to a negative association. There are no studies to investigate the association between BMI and EOC incidence. Moreover, the impact of other lifestyle factors like alcohol consumption and physical activity, which might have interactions with BMI, remains unclear.

Our study aims to evaluate the association between $\mathrm{BMI}$ and the incidence of EOC in the largest prospective population-based study in Australia. We present the following article in accordance with the STROBE reporting checklist (available at https://dx.doi.org/10.21037/atm-212775).

\section{Methods}

Ethics approval for the 45 and Up Study was granted by the University of New South Wales Human Research Ethics Committee. Ethics approval for this specific study was granted by the Royal Victorian Eye and Ear Hospital Human Research Ethics Committee (17/1330HS/20). The study was conducted in accordance with the Declaration of Helsinki (as revised in 2013).

\section{Participants}

The Sax Institute's 45 and Up Study is a large-scale prospective cohort study with a total of 267,153 participants aged 45 years and over residing in New South Wales (NSW), Australia. This study recruited participants randomly selected from the Services Australia (formerly the Australian Government Department of Human Services) Medicare enrollment database, accounted for an estimated $10 \%$ of the NSW population. During the baseline recruitment process between January 2006 and December 2009, the eligible participants filled out postal questionnaires and provided signed consent for the linkage of their information to other health databases, such as the Medicare Benefits Schedule (MBS) database that collated claims records for diagnostic tests and procedures during the follow-up period. The methodology of the 45 and Up Study has been introduced elsewhere in detail (6).

The present study included participants aged 45 55 years at baseline. We excluded participants with a history of cataract surgery prior to baseline based on previous claims of cataract surgery on the MBS database or the responses on the baseline questionnaires, those with missing weight or height data, those with physical function scores lower than 25 , those with a BMI less than $18.5 \mathrm{~kg} / \mathrm{m}^{2}$ or more than $50 \mathrm{~kg} / \mathrm{m}^{2}$, and all those who underwent any ocular surgery during the follow-up period. Figure 1 gives a detailed description of the selection process.

\section{Outcome}

Cataract surgery was defined as the Current Procedural Terminology codes (42698 and 42702) and linked with participants' data in the MBS database. EOC was defined as cataract surgically treated prior to 65 years of age. The follow-up period was defined as the time elapsed from the baseline date, to the date of cataract surgery or December 31, 2016, whichever came first. Participants who did not have the MBS claims records of cataract surgery during the follow-up period were deemed to be cataract-free for the purposes of this study.

\section{Exposures}

The BMI data were obtained from the self-reported height and weight in response to the questions "How tall are you without shoes?" and "About how much do you weigh?". The BMI was calculated as the weight (in kilograms) divided by the square of the height (in meters), which was previously validated in a sub-sample of the 45 and $U p$ Study (7). According to the body weight classification by World Health Organization (WHO) and the distribution of participants in the present study (8), BMI was divided into seven categories including $18.5-19.99,20-22.49$, and 22.5$24.99 \mathrm{~kg} / \mathrm{m}^{2}$ (normal weight); $25-27.49$ and $27.5-29.99 \mathrm{~kg} / \mathrm{m}^{2}$ (overweight); and 30-32.49 and $32.5-50 \mathrm{~kg} / \mathrm{m}^{2}$ (obese). 


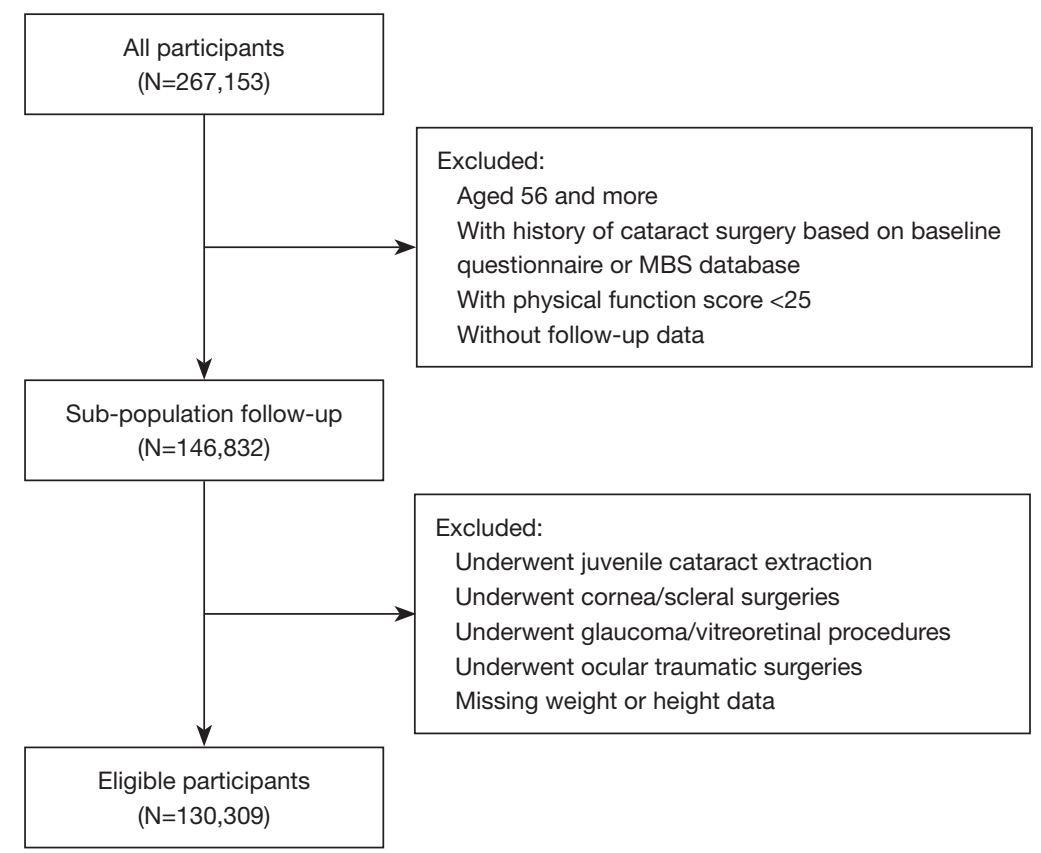

Figure 1 Participant selection flowchart. MBS, Medicare Benefits Schedule.

\section{Covariates}

The covariates included self-reported baseline responses for age, gender, ethnicity (whites or non-whites), household income, education level, smoking status, alcohol intake, physical activity (PA), history of cardiovascular disease (yes/ no), history of diabetes (yes/no), and history of hypertension (yes/no). The classifications of covariates referred to the baseline questionnaire and the distributions of participants. Household income was classified into four groups: $<\$ 20,000, \$ 20,000-39,999, \$ 40,000-69,999$, and $>\$ 70,000$, measured in Australian dollars (AUD). The highest level of education attained was classified into three groups: $<10$ years, high school, and university or higher. Smoking was categorized into the three groups: never smoker, former smoker, and current smoker. Alcohol intake was classified into five groups organized by the number of drinks per week: $0,1-4,5-7,8-14$, or $\geq 15$ drinks. The PA in minutes per week was classified into five groups: 0, 1-149, 150-299, $300-539$, and $\geq 540$ minutes per week.

\section{Statistical analysis}

The number of cases with EOC was divided by personyears to evaluate the incidence rate of EOC. The baseline characteristics of the participants were stratified based on
BMI categories with descriptive statistics, including mean \pm standard deviation (SD) and number (percent). The Cox hazards model was used to assess the effect of BMI on the risk of EOC. Hazard ratios (HRs) with 95\% confidence intervals (CI) were estimated for all categories of BMI, using a BMI of $20.0-22.49 \mathrm{~kg} / \mathrm{m}^{2}$ as the reference. Two regression models were used in the analysis: a first regression model adjusted for age and gender only, and a second model with further adjustment for all potential confounding factors including age, gender, ethnicity, income, education level, lifestyle factors (smoking, alcohol drinking and physical activity), and systematic diseases (hypertension, cardiovascular disease and diabetes). Sensitivity analyses were performed by restricting the population aged 45 to 50 at baseline. We also conducted subgroup analyses stratified by gender, ethnicity, education level, smoking status, alcohol consumption, PA, and systematic diseases (hypertension, cardiovascular disease and diabetes). A two-tailed $\mathrm{P}$ value of $<0.05$ was used as the level of statistical significance for all comparisons. All analyses were completed using the SAS software package (SAS 9.3; SAS Institute, Cary, NC, USA).

\section{Results}

A total of 73,007 individuals aged 45 to 55 years in this prospective cohort were deemed eligible for the present 
analysis. A total of 1,764 participants underwent cataract surgery over 643,717 person-years with a mean follow-up period of 8.8 years, corresponding to an incidence rate of 2.72 cases per 1,000 person-years.

Significant statistical differences were observed in the distribution of characteristics among different BMI categories except for household income $(\mathrm{P}=0.864)$, which could be seen in Table 1. Comparisons of participants with normal weight (BMI 18.5-24.99 $\mathrm{kg} / \mathrm{m}^{2}$ ) showed that those who were overweight (BMI $>25 \mathrm{~kg} / \mathrm{m}^{2}$ ) tended to have lower education level, higher consumption of cigarettes and alcohol, shorter minutes of PA, and higher prevalence of cardiovascular disease, diabetes and hypertension $(\mathrm{P}<0.001)$.

Table 2 shows the HR and 95\% CI of EOC risk related to BMI categories. There were no significant associations between BMI and EOC adjusted for age and gender. Males with a BMI of $30.0-32.49 \mathrm{~kg} / \mathrm{m}^{2}$ showed a $54 \%$ higher risk of EOC compared with those with a BMI of 20.0 $22.49 \mathrm{~kg} / \mathrm{m}^{2}$. When further adjustments were made for all potential confounding factors (Model 2), no statistically significant associations were observed between BMI and EOC in total, and in analyses stratified by gender.

Table 3 shows the associations between BMI and EOC stratified by gender, ethnicity, education level, smoking status, alcohol consumption, PA, and systematic diseases (hypertension, cardiovascular disease and diabetes). Among participants who drank 5 to 7 alcoholic drinks per week, a $73 \%$ and $27 \%$ reduction in the risk of EOC was observed in participants with a BMI of 18.5-19.99 and $25.0-27.49 \mathrm{~kg} / \mathrm{m}^{2}$, respectively, compared to those with a BMI of $20.0-22.49 \mathrm{~kg} / \mathrm{m}^{2}$. No significant associations were observed between the incidence of EOC and BMI after data were stratified by other confounding factors.

The sensitivity analysis on participants aged $45-50$ years at baseline (Table 4) demonstrates similar results to the main analysis, showing that BMI was not significantly associated with EOC incidence.

\section{Discussion}

Our analysis of the 10-year follow-up data from the largescale prospective 45 and Up Study cohort observed no significant association between $\mathrm{BMI}$ and the incidence of EOC. The only statistically significant relationships suggested that the consumption of 5-7 alcoholic drinks per week may be a protective factor against EOC for people with a BMI of $18.5-19.99$ or $25.0-27.49 \mathrm{~kg} / \mathrm{m}^{2}$.

To the best of our knowledge, our study is the first to specifically investigate the association between $\mathrm{BMI}$ and EOC in a prospective population-based cohort study, and we observe no significant association between them. Numerous previous studies have been conducted to investigate the impact of BMI on cataracts, however these have been conducted in the context of ARC, and no studies have done so on the subset of EOC. Unfortunately, even findings on the associations between $\mathrm{BMI}$ and $\mathrm{ARC}$ remain inconclusive. Some studies suggested that elevated BMI may increase the risk of ARC (9-14), but there were still controversies regarding which type of cataract demonstrated the strongest positive association. Conversely, other studies revealed a reduced $(15,16)$ risk of cataract in participants with increased BMI, or no significant relationship between BMI and cataract (17-19). Comparisons between previous studies have been largely limited by the wide variation in the definitions of BMI, confounding factors, as well as the follow-up duration. Regarding EOC, little is known about its etiology, risk factors, and mechanism. Possible risk factors reported in the literature include steroid use, sunlight exposure, diabetes, and trauma (20-23). No previous studies explored the association between BMI and EOC, and the present study identified there were no significant associations between them. Nevertheless, the role of BMI in EOC development still requires further research.

Oxidative damage and inflammation are recognized as key mechanisms of cataractogenesis (24), and have been assumed as plausible pathophysiological mechanisms linking cataract and higher BMI. The higher levels of leptin in plasma and the increased systemic inflammation in obese individuals, accompanied by an accumulation of reactive oxygen species and pro-inflammatory cytokines may promote the formation of cataracts (25-28). One potential explanation for the lack of any significant association between BMI and EOC in our study is that oxidative stress may not account for the main cause of EOC formation. There are a plethora of other factors that influence cataract formation, including the nutritional deprivation and lower socioeconomic status typically associated with lower BMIs, or the diabetes, hypertension, and other metabolic disorders seen with higher BMIs. The possibilities of residual confounding by diseases or factors related to the abovementioned circumstances cannot be excluded. Another explanation for our negative result is that the cataractogenic process stimulated by higher BMI may result in incremental biochemical changes in the lens that typically take place over a longer time, thus patients manifest as ARC rather 
Table 1 Baseline characteristics of eligible participants stratified by BMI categories

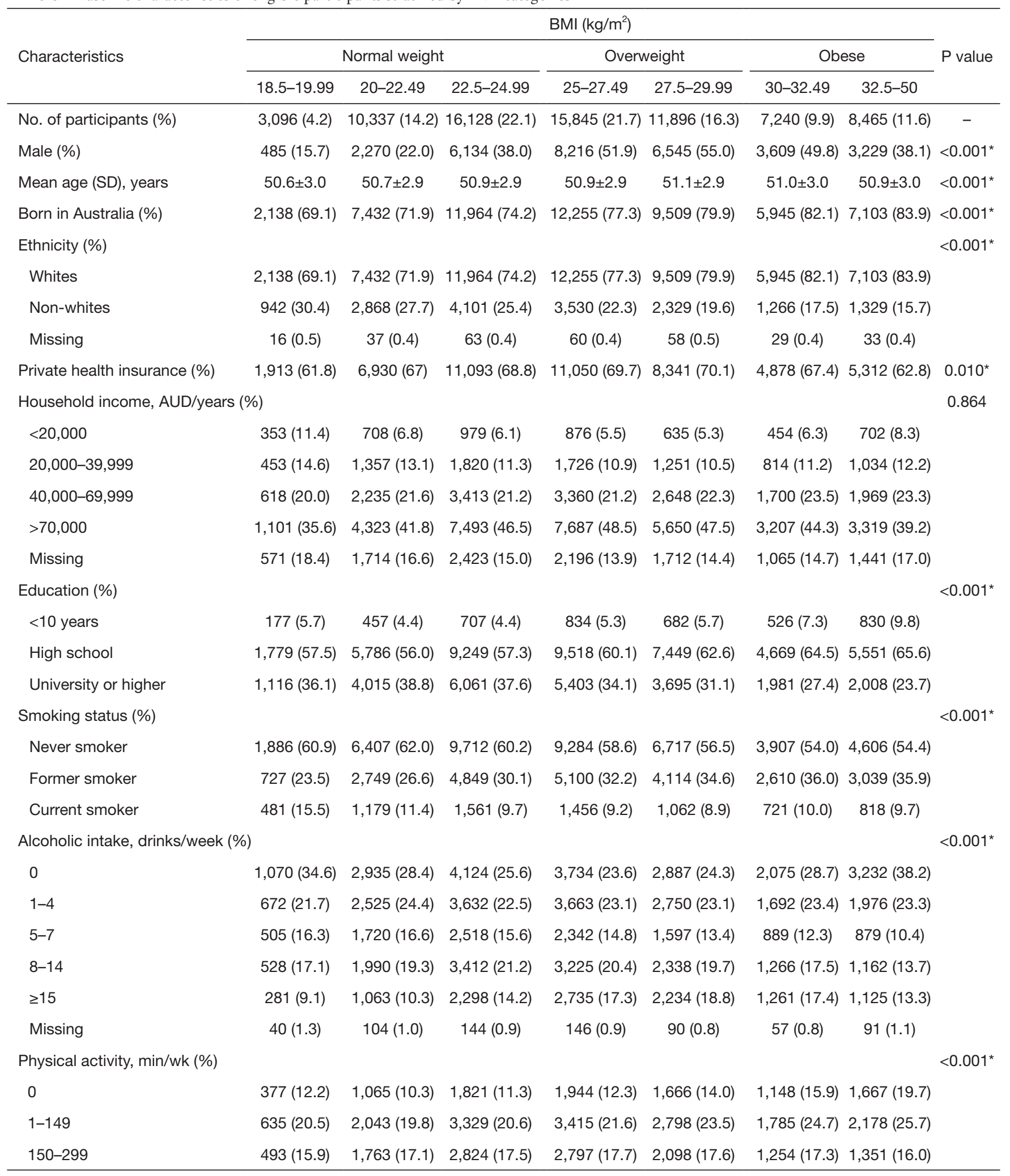

Table 1 (continued) 
Table 1 (continued)

\begin{tabular}{|c|c|c|c|c|c|c|c|c|}
\hline \multirow{2}{*}{ Characteristics } & \multicolumn{7}{|c|}{$\mathrm{BMI}\left(\mathrm{kg} / \mathrm{m}^{2}\right)$} & \multirow{2}{*}{$P$ value } \\
\hline & $18.5-19.99$ & $20-22.49$ & $22.5-24.99$ & $25-27.49$ & 27.5-29.99 & $30-32.49$ & $32.5-50$ & \\
\hline $300-539$ & $568(18.3)$ & $2,063(20.0)$ & $3,238(20.1)$ & $3,174(20.0)$ & $2,210(18.6)$ & $1,259(17.4)$ & 1,337 (15.8) & \\
\hline$\geq 540$ & $942(30.4)$ & 3,209 (31.0) & $4,635(28.7)$ & $4,221(26.6)$ & $2,882(24.2)$ & $1,640(22.7)$ & 1,684 (19.9) & \\
\hline \multicolumn{9}{|l|}{ Comorbidities (\%) } \\
\hline Cardiovascular disease & $64(2.1)$ & $248(2.4)$ & $369(2.3)$ & $477(3.0)$ & 455 (3.8) & $282(3.9)$ & $393(4.6)$ & $<0.001^{*}$ \\
\hline Diabetes & $45(1.5)$ & $155(1.5)$ & $329(2.0)$ & $409(2.6)$ & 467 (3.9) & $412(5.7)$ & 920 (10.9) & $<0.001^{*}$ \\
\hline Hypertension & $232(7.5)$ & $952(9.2)$ & $2,071(12.8)$ & 2,949 (18.6) & $2,927(24.6)$ & $2,251(31.1)$ & $3,449(40.7)$ & $<0.001^{*}$ \\
\hline
\end{tabular}

*, Statistically significant $(\mathrm{P}<0.05)$. BMI, body mass index; SD, standard deviation; AUD, Australian dollars; min/wk, minutes per week.

Table 2 Hazard ratios and $95 \%$ confidence intervals of early onset cataract surgery risk according to BMI categories at baseline

\begin{tabular}{|c|c|c|c|c|c|c|c|c|}
\hline \multirow{2}{*}{ Group } & \multirow{2}{*}{ BMI $\left(\mathrm{kg} / \mathrm{m}^{2}\right)$} & \multirow{2}{*}{$\begin{array}{l}\text { No. of } \\
\text { cases }\end{array}$} & \multirow{2}{*}{$\begin{array}{c}\text { No. of } \\
\text { participants }\end{array}$} & \multirow{2}{*}{$\begin{array}{c}\text { No. of } \\
\text { person-years }\end{array}$} & \multicolumn{2}{|c|}{ Model $1^{a}$} & \multicolumn{2}{|c|}{ Model $2^{\mathrm{b}}$} \\
\hline & & & & & $\mathrm{HR}(95 \% \mathrm{Cl})$ & $P$ value & $\mathrm{HR}(95 \% \mathrm{Cl})$ & $P$ value \\
\hline \multirow[t]{5}{*}{ Overall } & $18.5-19.99$ & 68 & 3,096 & $27,337.1$ & $0.87(0.67-1.13)$ & 0.300 & $0.89(0.67-1.18)$ & 0.413 \\
\hline & 20.0-22.49 & 265 & 10,337 & $91,214.7$ & 1.0 (ref) & & 1.0 (ref) & \\
\hline & 22.5-24.99 & 364 & 16,128 & $142,345.2$ & $0.89(0.76-1.05)$ & 0.156 & $0.88(0.75-1.04)$ & 0.129 \\
\hline & $30.0-32.49$ & 210 & 7,240 & $63,715.74$ & $1.16(0.96-1.39)$ & 0.118 & $1.03(0.85-1.26)$ & 0.759 \\
\hline & $32.5-50$ & 205 & 8,465 & $74,444.41$ & $0.96(0.80-1.15)$ & 0.650 & $0.86(0.70-1.05)$ & 0.141 \\
\hline \multirow[t]{4}{*}{ Male } & 18.5-19.99 & 68 & 3,096 & $4,328.26$ & $0.83(0.39-1.76)$ & 0.626 & $1.07(0.50-2.28)$ & 0.862 \\
\hline & 27.5-29.99 & 280 & 11,896 & $57,671.73$ & $1.17(0.83-1.63)$ & 0.367 & $1.01(0.71-1.45)$ & 0.935 \\
\hline & $30.0-32.49$ & 210 & 7,240 & $31,801.66$ & $1.54(1.08-2.18)$ & $0.016^{*}$ & $1.29(0.88-1.87)$ & 0.187 \\
\hline & $32.5-50$ & 205 & 8,465 & $28,370.17$ & $1.32(0.92-1.91)$ & 0.137 & $1.05(0.70-1.57)$ & 0.813 \\
\hline \multirow[t]{5}{*}{ Female } & $18.5-19.99$ & 68 & 3,096 & $23,008.84$ & $0.87(0.65-1.15)$ & 0.320 & $0.86(0.64-1.16)$ & 0.328 \\
\hline & 20.0-22.49 & 265 & 10,337 & $71,058.56$ & 1.0 (ref) & & 1.0 (ref) & \\
\hline & 22.5-24.99 & 364 & 16,128 & $88,004.79$ & $0.89(0.74-1.07)$ & 0.226 & $0.89(0.73-1.07)$ & 0.216 \\
\hline & 25.0-27.49 & 372 & 15,845 & $67,252.23$ & $0.90(0.75-1.09)$ & 0.299 & $0.88(0.72-1.08)$ & 0.224 \\
\hline & 27.5-29.99 & 280 & 11,896 & $47,061.54$ & $0.87(0.71-1.08)$ & 0.221 & $0.85(0.68-1.06)$ & 0.152 \\
\hline
\end{tabular}

a, Model 1 was adjusted for age and gender. ${ }^{\mathrm{b}}$, Model 2 was adjusted for age, gender, ethnicity, income, education level, lifestyle factors (smoking, alcohol drinking and physical activity), and systemic diseases (hypertension, cardiovascular disease and diabetes). *, statistically significant $(\mathrm{P}<0.05)$. BMI, body mass index; HR, hazard ratio; 95\% $\mathrm{Cl}, 95 \%$ confidence interval. 
Table 3 Multivariate-adjusted cox regression analyses stratified by covariates

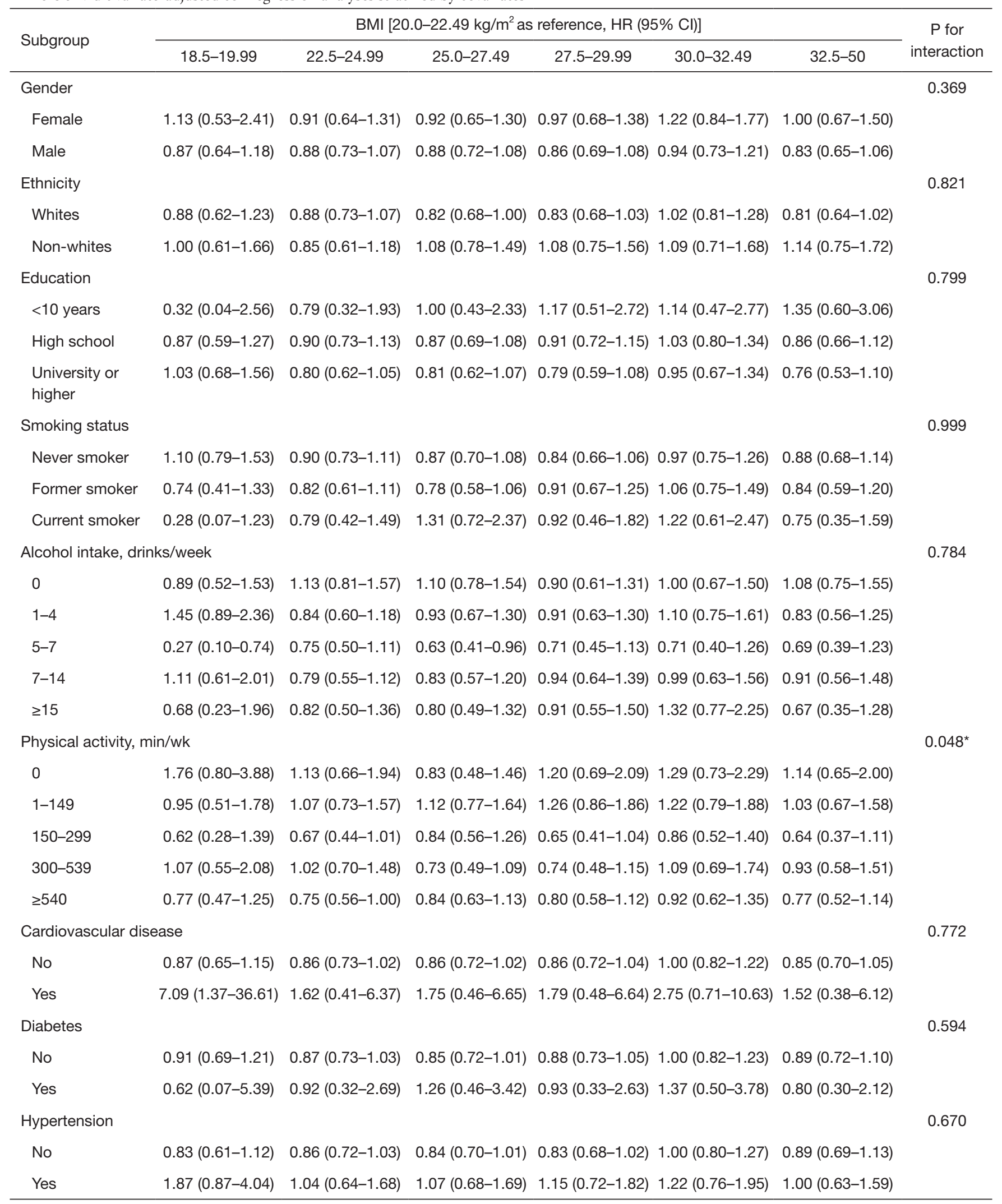

$\mathrm{BMI}$, body mass index; $\mathrm{HR}$, hazard ratio; $95 \% \mathrm{Cl}$, 95\% confidence interval; min/wk, minutes per week. 
Table 4 Sensitivity analysis by restricting for population aged $45-50$ at baseline

\begin{tabular}{|c|c|c|c|c|}
\hline BMI $\left(\mathrm{kg} / \mathrm{m}^{2}\right)$ & \multicolumn{2}{|c|}{ Model $1^{a}$} & \multicolumn{2}{|c|}{ Model $2^{b}$} \\
\hline $18.5-19.99$ & $0.73(0.41-1.28)$ & 0.269 & $0.71(0.39-1.30)$ & 0.269 \\
\hline 20.0-22.49 & 1.00 (ref) & & 1.00 (ref) & \\
\hline 22.5-24.99 & $0.98(0.71-1.36)$ & 0.925 & $0.93(0.66-1.30)$ & 0.676 \\
\hline 27.5-29.99 & $1.05(0.73-1.49)$ & 0.804 & $0.99(0.68-1.44)$ & 0.968 \\
\hline $30.0-32.49$ & $1.28(0.87-1.88)$ & 0.213 & $1.12(0.75-1.70)$ & 0.575 \\
\hline $32.5-50$ & $1.06(0.73-1.56)$ & 0.746 & $0.94(0.62-1.42)$ & 0.757 \\
\hline
\end{tabular}

${ }^{a}$, Model 1 was adjusted for age and gender. ${ }^{b}$, Model 2 was adjusted for age, gender, ethnicity, income, education level, lifestyle factors (smoking, alcohol drinking and physical activity), and systematic diseases (hypertension, cardiovascular disease and diabetes). BMI, body mass index; HR, hazards ratio; $\mathrm{Cl}$, confidence interval.

than EOC. Further research is therefore needed to confirm our findings.

Our study observed that alcohol intake within a certain range may be beneficial for reducing the risk of EOC, when we investigated the associations between BMI and EOC stratified by alcohol intake. An U-shape association, which usually refers to the nonlinear relationship, between alcohol intake and clinical disorders is often observed in epidemiologic studies, for example, the relationship between alcohol and cardiovascular diseases (29). Similar results regarding the association between $\mathrm{BMI}$ and cataracts were found in a meta-analysis (30). Moderate consumption may be protective, whereas heavy alcohol consumption becomes a significant risk factor of ARC, which is consistent with our results. As far as we know, no existing researches investigated the relationship between alcohol consumption and EOC incidence specifically, necessitating future researches in this area.

The strengths of the present study include the large sample size, prospective cohort design, long-term followup, and comprehensive assessment of a wide range of potential confounding factors. However, some potential limitations should be noted. Firstly, information regarding cataract sub-types could not be assessed by nature of the self-reported questionnaire responses, and it is possible that some EOC patients may have been omitted from the analysis as they had not undergone surgery. We chose cataract surgery as an endpoint to ensure only visually significant cataracts were measured. Meanwhile, it can also minimize the misclassification of patients with ARC that onset at an early age, but progress slowly. Secondly,
BMI was calculated based on self-reported height and weight at baseline. Bias exists as a tendency to overestimate height and underestimate weight (31). Also, subsequent changes to weight and the duration of obesity could not be incorporated, which may influence the risk estimation of the true association between BMI and EOC. However, the self-reported BMI measures have been validated in other studies and have showed reasonable agreement with more accurate BMI measurements $(7,32)$. Thirdly, other measures of obesity, for example, waist-to-hip ratio, were not taken in our study. Fourthly, only cataract surgeries performed in private Australian settings could be assessed from the MBS database. However, the majority of Australian surgeries during the study period occurred in private settings, accounting for $72 \%$ of total cataract surgeries, which reduces the impact of bias (33). Finally, participants' history of cataract surgery prior to 2004 was unknown, and it may be possible that some EOC cases were missed. The exclusion of participants aged 56 years and older, who were most likely to have undergone cataract surgery before 2004, partly reduced the likelihood of this bias. The possible underestimation of the actual risk should be noted in this population, considering the abovementioned limitations.

In conclusion, this prospective cohort study found no significant associations between BMI and the incidence of EOC. Moreover, moderate drinking appeared to be potentially protective against EOC. Further studies are required to confirm the present study's findings and explain the underlying mechanisms of any link between BMI and EOC. 


\section{Acknowledgments}

This research was completed using data collected through the 45 and Up Study (www.saxinstitute.org.au). The 45 and Up Study is managed by the Sax Institute in collaboration with major partner Cancer Council NSW, and partners: the National Heart Foundation of Australia (NSW Division); NSW Ministry of Health; NSW Government Family \& Community Services-Aging, Carers and the Disability Council NSW; and the Australian Red Cross Blood Service. We acknowledge that Services Australia supplied the Medicare Benefits Schedule (MBS) data to the Sax Institute. We thank the many thousands of people participating in the 45 and Up Study.

Funding: Professor Mingguang He receives support from the University of Melbourne at Research Accelerator Program and the CERA Foundation. The Centre for Eye Research Australia (CERA) receives operational infrastructure support from the Victorian State Government. Professor Mingguang He is supported by NHMRC Investigator Grant (APP1175405) and by the Fundamental Research Funds of the State Key Laboratory in Ophthalmology, National Natural Science Foundation of China (81420108008). Professor Luo is supported by the Construction Project of High-Level Hospitals in Guangdong Province (303020102). The sponsor or funding organization had no role in the design or conduct of this research.

\section{Footnote}

Reporting Checklist: The authors have completed the STROBE reporting checklist. Available at https://dx.doi. org/10.21037/atm-21-2775

Data Sharing Statement: Available at https://dx.doi. org/10.21037/atm-21-2775

Peer Review File: Available at https://dx.doi.org/10.21037/ atm-21-2775

Conflicts of Interest: All authors have completed the ICMJE uniform disclosure form (available at https://dx.doi. org/10.21037/atm-21-2775). The authors have no conflicts of interest to declare.

Ethical Statement: The authors are accountable for all aspects of the work in ensuring that questions related to the accuracy or integrity of any part of the work are appropriately investigated and resolved. All the procedures in this study were arranged strictly with the approval of the Royal Victorian Eye and Ear Hospital Human Research Ethics Committee (17/1330HS/20). Written informed consents have been obtained from all participants. The study was conducted in accordance with the Declaration of Helsinki (as revised in 2013).

Open Access Statement: This is an Open Access article distributed in accordance with the Creative Commons Attribution-NonCommercial-NoDerivs 4.0 International License (CC BY-NC-ND 4.0), which permits the noncommercial replication and distribution of the article with the strict proviso that no changes or edits are made and the original work is properly cited (including links to both the formal publication through the relevant DOI and the license). See: https://creativecommons.org/licenses/by-nc-nd/4.0/.

\section{References}

1. Tsai SY, Hsu WM, Cheng CY, et al. Epidemiologic study of age-related cataracts among an elderly Chinese population in Shih-Pai, Taiwan. Ophthalmology 2003;110:1089-95.

2. Flaxman SR, Bourne RRA, Resnikoff S, et al. Global causes of blindness and distance vision impairment 19902020: a systematic review and meta-analysis. Lancet Glob Health 2017;5:e1221-34.

3. Chiang CC, Lin CL, Peng CL, et al. Increased risk of cancer in patients with early-onset cataracts: a nationwide population-based study. Cancer Sci 2014;105:431-6.

4. Wang SB, Mitchell P, Plant AJ, et al. Cataract surgery is more prevalent and occurs at an earlier age in a high cardiovascular risk cohort: Comparison with the Blue Mountains Eye Study. Int J Cardiol 2016;212:72-5.

5. Das GK, Boriwal K, Chhabra P, et al. Presenile cataract and its risk factors: A case control study. J Family Med Prim Care 2019;8:2120-3.

6. 45 and Up Study Collaborators; Banks E, Redman S, et al. Cohort profile: the 45 and up study. Int J Epidemiol 2008;37:941-7.

7. Ng SP, Korda R, Clements M, et al. Validity of selfreported height and weight and derived body mass index in middle-aged and elderly individuals in Australia. Aust N ZJ Public Health 2011;35:557-63.

8. World Health Organization (WHO). Global Database on Body Mass Index, 2006. 
9. Ye J, Lou LX, He JJ, et al. Body mass index and risk of age-related cataract: a meta-analysis of prospective cohort studies. PLoS One 2014;9:e89923.

10. Glynn RJ, Rosner B, Christen WG. Evaluation of risk factors for cataract types in a competing risks framework. Ophthalmic Epidemiol 2009;16:98-106.

11. Williams PT. Prospective epidemiological cohort study of reduced risk for incident cataract with vigorous physical activity and cardiorespiratory fitness during a 7-year follow-up. Invest Ophthalmol Vis Sci 2009;50:95-100.

12. Weintraub JM, Willett WC, Rosner B, et al. A prospective study of the relationship between body mass index and cataract extraction among US women and men. Int J Obes Relat Metab Disord 2002;26:1588-95.

13. Kuang TM, Tsai SY, Hsu WM, et al. Body mass index and age-related cataract: the Shihpai Eye Study. Arch Ophthalmol 2005;123:1109-14.

14. Hiller R, Podgor MJ, Sperduto RD, et al. A longitudinal study of body mass index and lens opacities. The Framingham Studies. Ophthalmology 1998;105:1244-50.

15. Leske MC, Wu SY, Nemesure B, et al. Risk factors for incident nuclear opacities. Ophthalmology 2002;109:1303-8.

16. Nirmalan PK, Robin AL, Katz J, et al. Risk factors for age related cataract in a rural population of southern India: the Aravind Comprehensive Eye Study. Br J Ophthalmol 2004;88:989-94.

17. Chang JR, Koo E, Agrón E, et al. Risk factors associated with incident cataracts and cataract surgery in the Agerelated Eye Disease Study (AREDS): AREDS report number 32. Ophthalmology 2011;118:2113-9.

18. Lindblad BE, Håkansson N, Philipson B, et al. Metabolic syndrome components in relation to risk of cataract extraction: a prospective cohort study of women. Ophthalmology 2008;115:1687-92.

19. Richter GM, Choudhury F, Torres M, et al. Risk factors for incident cortical, nuclear, posterior subcapsular, and mixed lens opacities: the Los Angeles Latino eye study. Ophthalmology 2012;119:2040-7.

20. Schwab IR, Armstrong MA, Friedman GD, et al. Cataract extraction. Risk factors in a health maintenance organization population under 60 years of age. Arch Ophthalmol 1988;106:1062-5.

21. Praveen MR, Shah GD, Vasavada AR, et al. A study to explore the risk factors for the early onset of cataract in India. Eye (Lond) 2010;24:686-94.
22. Jyothi R, Sathyan S. Etiopathogenesis of presenile cataracts in Central Kerala: A cross-sectional observational study. Kerala J Ophthalmol 2017;29:179-83.

23. Patel D, Ahuja N. Analysis Of presenile cataract risk factor and type of cataract. Int J Sci Res 2018;6:35-6.

24. Truscott RJ. Human cataract: the mechanisms responsible; light and butterfly eyes. Int J Biochem Cell Biol 2003;35:1500-4.

25. Muoio DM, Newgard CB. Obesity-related derangements in metabolic regulation. Annu Rev Biochem 2006;75:367-401.

26. Bouloumie A, Marumo T, Lafontan M, et al. Leptin induces oxidative stress in human endothelial cells. FASEB J 1999; 13:1231-8.

27. Ritchie SA, Connell JM. The link between abdominal obesity, metabolic syndrome and cardiovascular disease. Nutr Metab Cardiovasc Dis 2007;17:319-26.

28. Klein BE, Klein R, Lee KE, et al. Markers of inflammation, vascular endothelial dysfunction, and agerelated cataract. Am J Ophthalmol 2006;141:116-22.

29. Ronksley PE, Brien SE, Turner BJ, et al. Association of alcohol consumption with selected cardiovascular disease outcomes: a systematic review and meta-analysis. BMJ 2011;342:d671.

30. Gong Y, Feng K, Yan N, et al. Different amounts of alcohol consumption and cataract: a meta-analysis. Optom Vis Sci 2015;92:471-9.

31. Connor Gorber S, Tremblay M, Moher D, et al. A comparison of direct vs. self-report measures for assessing height, weight and body mass index: a systematic review. Obes Rev 2007;8:307-26.

32. Keith SW, Fontaine KR, Pajewski NM, et al. Use of selfreported height and weight biases the body mass indexmortality association. Int J Obes (Lond) 2011;35:401-8.

33. Australian Commission on Safety and Quality in Health Care. Cataract surgery. Available online: https:// www.safetyandquality.gov.au/search/cataract. Surgical interventions 2016: 305-14.

Cite this article as: Zhang J, Wang W, Yang G, Ha J, Tan X, Shang X, Zhu Z, Han X, Liu Z, Zhang L, He M, Luo L. Body mass index is not associated with early onset cataract in the 45 and Up cohort study. Ann Transl Med 2021;9(22):1640. doi: 10.21037/atm-21-2775 